\title{
Duality of $\beta$-glucan microparticles: antigen carrier and immunostimulants
}

This article was published in the following Dove Press journal:

International Journal of Nanomedicine

31 May 2016

Number of times this article has been viewed

\author{
Kim Baert ${ }^{1}$ \\ Bruno G De Geest ${ }^{2}$ \\ Henri De Greve 3,4 \\ Eric Cox',* \\ Bert Devriendt ${ }^{1, *}$ \\ 'Department of Virology, Parasitology \\ and Immunology, ${ }^{2}$ Department of \\ Pharmaceutics, Ghent University, \\ Merelbeke, Ghent, Belgium; \\ ${ }^{3}$ Structural Biology Research Centre, \\ VIB, Brussels, Belgium; ${ }^{4}$ Structural \\ Biology Brussels, Vrije Universiteit \\ Brussel, Brussels, Belgium \\ *These authors contributed equally \\ to this work
}

\begin{abstract}
Designing efficient recombinant mucosal vaccines against enteric diseases is still a major challenge. Mucosal delivery of recombinant vaccines requires encapsulation in potent immunostimulatory particles to induce an efficient immune response. This paper evaluates the capacity of $\beta$-glucan microparticles (GPs) as antigen vehicles and characterizes their immune-stimulatory effects. The relevant infectious antigen FedF was chosen to be loaded inside the microparticles. The incorporation of FedF inside the particles was highly efficient (roughly 85\%) and occurred without antigen degradation. In addition, these GPs have immunostimulatory effects as well, demonstrated by the strong reactive oxygen species (ROS) production by porcine neutrophils upon their recognition. Although antigen-loaded GPs still induce ROS production, antigen loading decreases this production by neutrophils for reasons yet unknown. However, these antigen-loaded GPs are still able to bind their specific $\beta$-glucan receptor, demonstrated by blocking complement receptor 3 , which is the major $\beta$-glucan receptor on porcine neutrophils. The dual character of these particles is confirmed by a T-cell proliferation assay. FedF-loaded particles induce a significantly higher FedF-specific T-cell proliferation than soluble FedF. Taken together, these results show that GPs are efficient antigen carriers with immune-stimulatory properties.
\end{abstract}

Keywords: $\beta$-glucan microparticles, FedF, antigen delivery vehicle, immunostimulants

\section{Introduction}

Mucosal vaccination is the most efficient way to protect human and animals against enteric infections. However, the development of effective mucosal vaccine subunits encounters multiple challenges, such as antigen damaging and limited immunogenicity. ${ }^{1-4}$ The encapsulation of antigens in microparticles is a promising approach to overcome these problems, as they can protect the antigens against degradation as well as carry potent adjuvants or immune modulators to enhance the immunogenicity. ${ }^{5-7}$ Frequently used particle systems for oral immunization are those based on poly(lactic-co-glycolic acid); however, low antigen encapsulation efficiency and antigen degradation during their formation limit their use in commercial vaccines. ${ }^{8}$ On the contrary, $\beta$-glucan microparticles (GPs) are emerging microparticles known for their safety, immunogenicity, and high antigen encapsulation efficiency. ${ }^{9-18}$ These promising antigen carriers are derived from the cell wall of Saccharomyces cerevisiae (Baker's yeast) and are composed of $>85 \% \beta$-1,3-D-glucan polymers ( $\beta$-glucans), $\sim 2 \%$ chitin, and $<1 \%$ lipids and proteins, with the rest being mostly ash and moisture. ${ }^{15}$ The main component of these particles, the $\beta$-glucans, is a "microbe-associated molecular pattern", which is very interesting in vaccine development for its immunostimulating characteristics. ${ }^{19,20}$ We have previously reported that particulate $\beta$-glucans are mainly recognized by complement receptor 3 (CR3) on porcine innate immune cells and require the signaling molecule
Laboratory of Immunology, Department of Virology, Parasitology and Immunology, Ghent University, Salisburylaan I33, 9820 Merelbeke, Ghent, Belgium Tel +3292647343

Email b.devriendt@ugent.be (c) (1) (-) 2016 Baert et al. This work is published and licensed by Dove Medical Press Limited. The full terms of this license are available at https://www.dovepress.com/terms.php (c) hereby accept the Terms. Non-commercial uses of the work are permitted without any further permission from Dove Medical Press Limited, provided the work is properly attributed. For permission for commercial use of this work, please see paragraphs 4.2 and 5 of our Terms (https://www.dovepress.com/terms.php). 
FAK to carry out their immunostimulatory responses. ${ }^{21}$ However, the receptor involved in the immunostimulating characteristics of GPs is not yet known. Many articles have described the strong potency of these GPs in eliciting

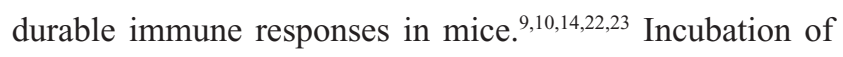
mouse bone marrow-derived dendritic cells with ovalbumin (OVA)-loaded GPs resulted in phagocytosis, upregulation of maturation markers, rapid proteolysis of OVA, and proliferation of OVA-reactive transgenic $\mathrm{CD} 8^{+} \mathrm{OT}-\mathrm{I}$ and $\mathrm{CD} 4^{+}$ OT-II T-cells. ${ }^{14}$ However, the immunological effect of these particles on porcine innate immune cells has not been investigated yet. Moreover, besides the incorporation of model antigens, no clinically relevant antigens were incorporated in these GPs. We have incorporated FedF, the tipadhesin of F18 fimbriae, inside the particles, since this antigen is one of the most important virulence factors of $\mathrm{F} 18^{+}$Escherichia coli. E. coli carrying the F18 fimbriae colonizes the small intestine of pigs and cause postweaning diarrhea (enterotoxigenic E. coli $[\mathrm{ETEC}]$ ) and edema disease (Shiga toxin-producing E. coli $[\mathrm{STEC}]$ ) in pigs, resulting in economic losses to the pig production industry. ${ }^{24}$ The bacteria adhere to the intestinal epithelial surface with their fimbriae and produce enterotoxins, which induce secretion of electrolytes and water. Porcine ETEC strains can produce five fimbrial types (F4, F18, F41, $\mathrm{F} 5$, and F6), of which F4 and F18 are most frequently associated with ETEC-induced diarrhea. ${ }^{25}$ The F18 fimbriae are polymeric proteins composed of several subunits: FedA is the structural subunit, while FedF is the tipadhesin mediating the binding of the bacteria to the epithelium. The FedF subunit of F18 fimbriae is located in a dedicated single-copy adhesin at the distal tip of the fimbriae. ${ }^{26}$ Tipadhesins are usually composed of two immunoglobulin (Ig)-like domains: an $\mathrm{N}$-terminal lectin or receptor binding module and a $\mathrm{C}$-terminal pilin. As it needs a complementary $\beta$-strand from the FedE subunit, using donor strand complementation is necessary to achieve a stable recombinant expression of FedF. ${ }^{27}$ To protect pigs against $\mathrm{F} 18^{+} \mathrm{ETEC}$ infections, local intestinal immunity is required. However, oral immunization with F18 fimbriae does not elicit protection in a piglet model, probably due to the presence of immunodominant epitopes in the FedA subunit. ${ }^{28}$ We reasoned that oral immunization of piglets with purified FedF subunit would enable induction of protective immunity, but only if FedF is encapsulated inside microparticles so asto deliver higher amounts of antigens to the gut-associated lymphoid tissue and to induce strong immune responses by mimicking pathogen dimensions.

So, we incorporated FedF inside GPs for oral administration to induce intestinal FedF-specific antibody responses.
In this study, we investigated the capacity of these GPs as both antigen vehicles and immunostimulants. Porcine immune cells were used as the translational model, because $\beta$-glucan recognition and signaling in porcine innate immune cells is closer related to humans than murine cells. ${ }^{21,29,30}$

\section{Experimental section Generation of FedF}

FedF was generated using the method of De Kerpel et al. ${ }^{27}$ Briefly, the $f e d F_{15-165}$ gene from F18 E. coli 107/86 strain was cloned in the pDEST14 vector under a T7 promotor. The gene was C-terminal truncated and then transformed into E. coli strain C43 (DE3). The C43 (DE3) cells were grown, induced with $1 \mathrm{mM}$ isopropyl $\beta$-D-1thiogalactopyranoside, and incubated for 2 hours. Cells were subjected to osmotic shock and the periplasmic extract was loaded onto a Source 3S column (Amersham plc, Amersham, UK) for cation exchange in $20 \mathrm{mM}$ Tris ( $\mathrm{pH}$ 7.5). Proteins were eluted with $140 \mathrm{mM} \mathrm{NaCl}$ and further purified using gel filtration on a Superdex-75HR column in $10 \mathrm{mM}$ 4-(2-hydroxyethyl)-1-piperazineethanesulfonic acid (pH 7.0) and $150 \mathrm{mM} \mathrm{NaCl}$. Finally, the protein was dialyzed against $0.9 \%$ saline.

\section{Development of GPs and protein encapsulation}

To generate GPs, S. cerevisiae (Baker's yeast) was treated with alkali and acid and dried at $20^{\circ} \mathrm{C}-25^{\circ} \mathrm{C}$ following alcohol and acetone washing steps. ${ }^{14,15}$ The resulting GPs were hollow and porous biomimetic $2-5 \mu \mathrm{m}$ particles consisting of $>85 \% \beta-1,3$-D-glucan polymers ( $\beta$-glucans), $\sim 2 \%$ chitin, and $<1 \%$ lipids and proteins, with the rest being mostly ash and moisture. ${ }^{15}$ Subsequently, these GPs were loaded with FedF as previously described. ${ }^{14}$ Briefly, $10 \mathrm{mg}$ of dry GPs were swollen with $5 \mathrm{mg}$ FedF dissolved in $0.9 \%$ saline $(1.25 \mathrm{~mL})$ for 2 hours at $4^{\circ} \mathrm{C}$, followed by lyophilization. These dry GP-FedF preparations were reswollen with $300 \mu \mathrm{L}$ aqua dest to maximize FedF diffusion into the GPs. Upon relyophilisation, FedF was trapped inside the GPs by adding $350 \mu \mathrm{L}$ of $25 \mathrm{mg} / \mathrm{mL}$ transfer RNA (derived from torula yeast) in Tris, EDTA, and $\mathrm{NaCl}$ buffer $(50 \mathrm{mM}$ Tris $\mathrm{HCl}$ with $2 \mathrm{mM}$ ethylenediaminetetraacetic acid and $0.15 \mathrm{M}$ $\mathrm{NaCl}, \mathrm{pH}$ 8.2) for 30 minutes at $50^{\circ} \mathrm{C}$. To complete the complexation reaction, another $500 \mu \mathrm{L}$ of $10 \mathrm{mg} / \mathrm{mL}$ transfer RNA was added to the particles. The suspension was centrifuged, washed four times in $0.9 \%$ saline, and stored at $-20^{\circ} \mathrm{C}(2.5 \mathrm{mg} / \mathrm{mL}) .{ }^{14}$ To calculate the amount of FedF trapped inside the GPs, the unbound FedF protein in the wash 
fractions was measured by a bicinchoninic acid assay against a bovine serum albumin standard $(0.05-1 \mathrm{mg} / \mathrm{mL})$.

\section{Western blotting}

Incorporation of FedF inside the particles was confirmed using a protein gel electrophoresis after digesting the GPs with $\beta$-1,3-D-glucanase from Helix pomatia (Sigma-Aldrich Co., St Louis, MO, USA). FedF-loaded GPs were first incubated in $\beta$-glucanases $(1 \mathrm{mg} / \mathrm{mL})$ diluted in $150 \mathrm{mM}$ sodium acetate buffer (Sigma-Aldrich Co.) for 24 hours at $37^{\circ} \mathrm{C}$. Proteins, released in the supernatants, were separated via sodium dodecyl sulfate-polyacrylamide gel electrophoresis consisting of a $12 \%$ separating gel and a $4 \%$ stacking gel. The gels were prepared by dissolving 30\% acrylamide in Tris ( $\mathrm{pH} 8.8$ ), 10\% sodium dodecyl sulfate, 10\% ammonium persulfate, and tetramethylethylenediamine. To load the samples, the proteins were mixed in equal volume ratios with the loading buffer containing $\beta$-mercaptoethanol and heated at $100^{\circ} \mathrm{C}$ for 5 minutes. Electrophoresis was performed at $28 \mathrm{~mA}$ for 1 hour. After separation, the proteins were transferred to a $0.45 \mu \mathrm{m}$ polyvinylidene fluoride membrane (GE Healthcare, Stockholm, Sweden) at $40 \mathrm{~V}$ for 2 hours. Next, the membrane was blocked (1 hour at room temperature) with $5 \%$ milk powder diluted in phosphate-buffered saline $+0.1 \%$ Tween ${ }^{\circledR} 20$ (Sigma-Aldrich Co.) to prevent antibodies from nonspecifically binding to the membrane. Monoclonal anti-mouse FedF-specific antibodies $(10 \mu \mathrm{g})$ were added overnight to the blot, followed by horseradish peroxidaseconjugated rabbit anti-mouse IgG (1/2,000; Dako, Denmark A/S Glostrup, Denmark) for 1 hour at room temperature. The bands were visualized using enhanced chemiluminescence (ECL) Western blotting substrate (Thermo Fisher Scientific, Waltham, MA, USA) and ChemiDOC ${ }^{\text {TM }}$ MP imaging system (Bio-Rad Laboratories Inc., Hercules, CA, USA).

\section{Oxidative burst by porcine neutrophils}

All animal experiments were approved by the animal care and ethics committee of the Faculty of Veterinary Medicine, Ghent University (Gent, Belgium; EC2013/62). Piglets (between 4 and 20 weeks old) were housed under standard conditions as blood donors. Peripheral blood was collected on heparin from the jugular vein of four pigs. Subsequently, neutrophils were isolated by density gradient centrifugation on a discontinuous Percoll gradient (68\% and 75\%; GE Healthcare) as described previously. ${ }^{31}$ To examine the immunostimulating characteristics of the particles, the ability of the GPs to induce an oxidative burst response by porcine neutrophils was investigated. The production of reactive oxygen species (ROS) was measured by the chemiluminescence assay described by Donne et $\mathrm{al}^{32}$ with some modifications. Neutrophils were seeded in a 96-well plate at $2.0 \times 10^{5}$ cells/ well in Roswell Park Memorial Institute (RPMI) without phenol red. The plates were incubated at $37^{\circ} \mathrm{C}$ for 2 hours in a humidified atmosphere with $5 \% \mathrm{CO}_{2}$ to allow the cells to adhere to the plastic surface. Subsequently, the supernatant was replaced by $175 \mu \mathrm{L}$ luminol $(0.5 \mathrm{mM})$. After 5 minutes of background measurement at $37^{\circ} \mathrm{C}, 25 \mu \mathrm{L}$ of the indicated GPs $(400,200$, or $100 \mu \mathrm{g} / \mathrm{mL})$ were added. Stimulation of the cells with phorbol myristate acetate (PMA; $50 \mu \mathrm{g} / \mathrm{mL}$ ) was used as a positive control. ROS production was then measured during 120 minutes in the integration mode. All stimulations were performed in duplicate. The ROS production is expressed as relative light units.

\section{Determination of the $\beta$-glucan receptor in porcine neutrophils}

To analyze the role of dectin-1 and CR3 in the immunostimulating characteristics of these GPs, the production of ROS by neutrophils was measured using the chemiluminescence assay (as already described) with some modifications. Neutrophils were seeded in a 96 -well plate at $2.0 \times 10^{5}$ cells/well. The plates were incubated at $37^{\circ} \mathrm{C}$ for 2 hours in a humidified atmosphere with $5 \% \mathrm{CO}_{2}$ to allow the cells to adhere to the plastic surface. Then, the cells were pretreated with the $\beta$-glucan receptor inhibitors for 1 hour at $37^{\circ} \mathrm{C}$. To inhibit dectin-1, laminarin $(1 \mathrm{mg} / \mathrm{mL})$ was added to the cells. To inhibit CR3-mediated responses, monoclonal antibodies (mAbs; mouse $\mathrm{IgG}_{1}$ isotypes) against CD18 (5 $\mathrm{g} / \mathrm{mL})$ and CD11R3 (15 $\mu \mathrm{g} / \mathrm{mL})$ (Bio-Rad Laboratories Inc.) were added. These antibodies were dialyzed against phosphate-buffered saline to remove sodium azide. An isotype-matched $\mathrm{mAb}$ control $\left(\mathrm{IgG}_{1}\right)$ was added to the cells to measure background inhibition. Subsequently, luminol was added to the cells $(0.5 \mathrm{mM}$ diluted in Hanks' balanced salt solution $+\mathrm{Ca}^{2+} \mathrm{Mg}^{2+}$ ), and, after 5 minutes of background measurement at $37^{\circ} \mathrm{C}, 25 \mu \mathrm{L}$ of GPs $(200 \mu \mathrm{g} / \mathrm{mL})$ was added. Stimulation of the cells with PMA $(50 \mu \mathrm{g} / \mathrm{mL})$ was used as a positive control. ROS production was then measured after 120 minutes in the integration mode. All stimulations were performed in duplicate. ROS production is expressed as relative light units.

\section{Generation of monocyte-derived dendritic cells}

Peripheral blood monomorphonuclear cells (PBMCs) were isolated by density gradient centrifugation on Lymphoprep (Nycomed Pharma AS, Thermo Fisher Scientific). 
Furthermore, monocytes were enriched from the PBMCs to a purity of $>95 \%$ by positive immunomagnetic bead selection (MACS; Miltenyi Biotec, Bergisch Gladbach, Germany) using the anti-SIRP $\alpha$ monoclonal antibody (clone 74-12-15a ${ }^{33}$ ). These cells were seeded in a 24-well plate at a density of $0.5 \times 10^{6}$ cells $/ \mathrm{mL}$ in monocyte-derived dendritic cell (MoDC) medium (Dulbeccos' Modified Eagle Medium supplemented with 10\% fetal calf serum, $1 \%$ penicillin-streptomycin, recombinant porcine $1 / 200$ $\mathrm{GM}^{-\mathrm{CSF}^{34}}$ and $5 \mathrm{ng} / \mathrm{mL}$ IL-4). After 3 days incubation at $37^{\circ} \mathrm{C}$ in a humidified atmosphere at $5 \% \mathrm{CO}_{2}$, fresh medium supplemented with GM-CSF and IL-4 at the same concentration to cells was added to generate MoDCs as previously described. ${ }^{35}$

\section{Antigen presentation assay}

To investigate whether incorporation of FedF inside the particles is necessary to induce FedF-specific cellular immune responses, a coculture of MoDCs and $\mathrm{CD}^{+} \mathrm{T}$-cells was set up. So, T-cells isolated from pigs immunized intramuscularly with $250 \mu \mathrm{g}$ purified FedF in incomplete Freund's adjuvant were used. ${ }^{36} \mathrm{CD}^{+} \mathrm{T}$-cells were enriched from PBMCs to a purity of $>95 \%$ by positive immunomagnetic selection with the $\alpha-\mathrm{CD} 6 \mathrm{mAb}\left(\mathrm{IgG}_{1}\right.$, clone $\left.\mathrm{a} 38 \mathrm{~b} 2^{37}\right)$ and goat anti-mouse microbeads (MACS, Miltenyi Biotec). MoDCs were stimulated with $8 \mu \mathrm{g}$ FedF or FedF-loaded GPs $(8 \mu \mathrm{g}$ FedF encapsulated) for 24 hours or left untreated (control). These stimulated MoDCs were subsequently cocultured at titrated numbers with $1.0 \times 10^{5}$ autologous $\mathrm{CD}^{+} \mathrm{T}$-cells for 5 days, and then the $[3 \mathrm{H}]$ methyl-thymidine $(1 \mu \mathrm{Ci} /$ well; Amersham plc) incorporation (18 hours) was measured using a $\beta$-scintillation counter (PerkinElmer Inc., Waltham, MA, USA).

\section{Statistics}

Data are presented as the mean \pm standard error of the mean. Data were analyzed with GraphPad Prism 5 (GraphPad Software, Inc., La Jolla, CA, USA) using the paired $t$-test for comparison of two data and using a repeated measures analysis of variance (post hoc: Tukey) for comparison of multiple data sets. Data were considered significant at $P<0.05$.

\section{Results and discussion Efficient loading of FedF inside GPs}

To assess if loading of FedF into GPs affects the antigenicity, we performed Western blotting. FedF was incorporated inside the GPs with a loading efficiency of $84.53 \% \pm 2.89 \%$, thereby confirming the high loading efficiency of the GPs (Figure 1A). Furthermore, we examined by gel electrophoresis the correct incorporation of FedF inside the particles. Therefore, we first destroyed the $\beta$-glucan particles by $\beta$-glucanases, after which the supernatants with the released antigens were loaded on a protein gel electrophoresis and detected by monoclonal FedF-specific antibodies (clone IMM04 $\left.{ }^{38}\right)$. Figure $1 \mathrm{~B}$ illustrates the protein FedF in lane 1
A

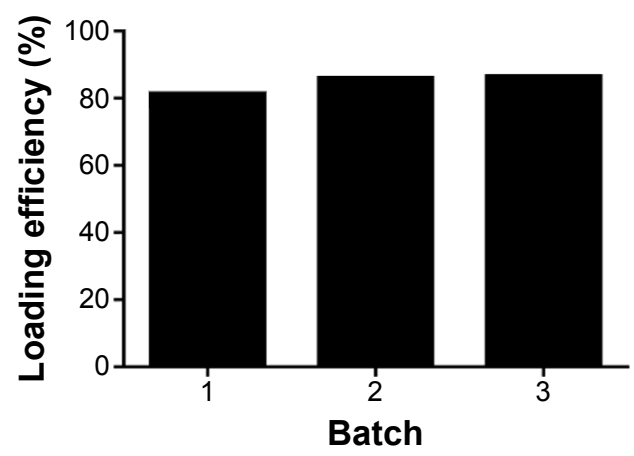

B

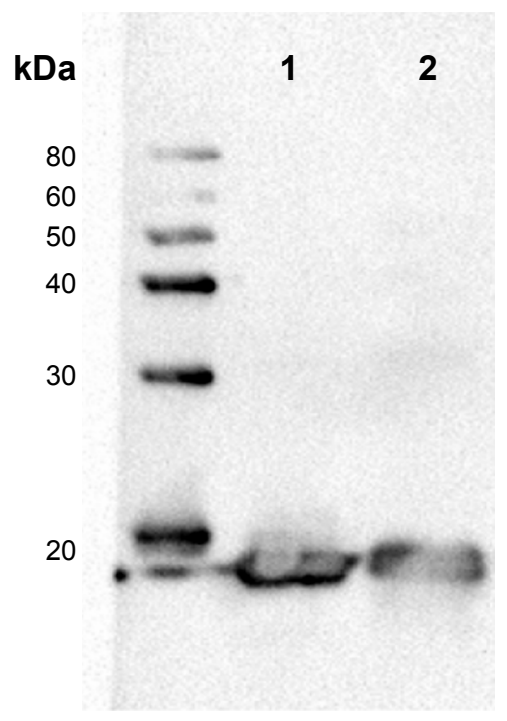

Figure I FedF was efficiently incorporated inside GPs.

Notes: (A) The loading efficiency of FedF inside GPs was determined by BCA. Therefore, the unbound FedF protein in the wash fractions was measured by BCA against a BSA standard $(0.05-1 \mathrm{mg} / \mathrm{mL})$. (B) FedF incorporation inside the GPs was analyzed by Western blotting after digesting the particles with $\beta$-glucanases. FedF was detected with specific monoclonal antibodies against FedF. Lane I illustrates FedF, while the FedF released from the GPs upon digestion is shown in lane 2.

Abbreviations: GPs, $\beta$-glucan microparticles; BCA, bicinchoninic acid assay; BSA, bovine serum albumin. 


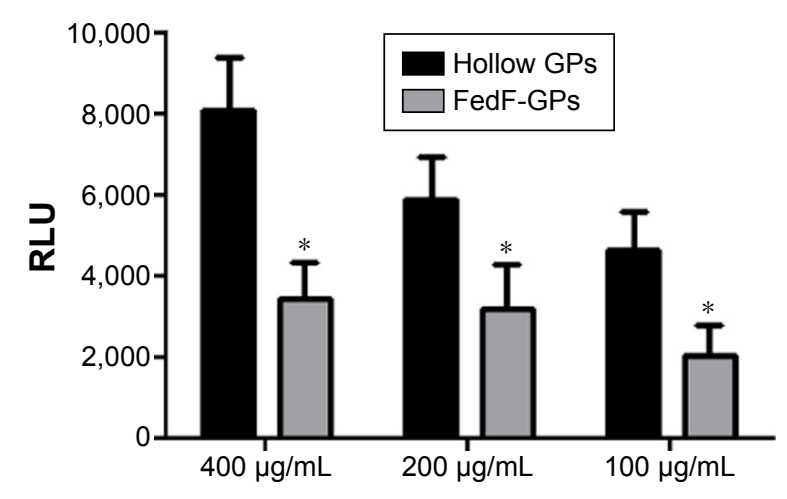

Figure 2 FedF-loaded GPs still possess their adjuvant function.

Notes: Neutrophils $\left(2 \times 10^{5}\right.$ cells) were stimulated with GPs at the indicated concentrations. ROS production was determined via chemiluminescence. Data are shown as the mean RLU \pm SEM of four pigs. ${ }^{*} P<0.0$ I.

Abbreviations: GPs, $\beta$-glucan microparticles; RLU, relative light units; ROS, reactive oxygen species; SEM, standard error of the mean.

and the FedF released from the digested GPs in lane 2. As shown, both FedF and the released FedF migrate near the expected molecular weight of $18 \mathrm{kDa}$. No degradation is visible, indicating the correct incorporation of FedF inside the particles. On the basis of these results, we conclude that FedF is efficiently incorporated inside the particles.

\section{FedF-loaded GPs still possess immune-stimulatory effects}

To assess the effect of antigen loading on the inherent immunostimulating characteristics of the GP, we determined the oxygen radical production of porcine neutrophils after stimulation with antigen-loaded particles. Figure 2 demonstrates that FedF-loaded GPs possess immune-stimulatory effects. Interestingly, hollow GPs could stimulate ROS production by neutrophils more than antigen-loaded particles, indicating that antigen loading partially masks the $\beta$-glucans of the particles from recognition by their receptors, dectin-1, and CR3. ${ }^{21}$

\section{The immune-modulatory effects of GPs are mainly mediated by binding to the $\alpha$-subunit of CR3}

We further investigated which $\beta$-glucan receptor is involved in the particle-induced activation of porcine neutrophils. As shown in Figure 3, the GPs-induced ROS production by neutrophils was significantly inhibited in the presence of anti-CD11R3 as compared to its isotype-matched control. In contrast to the $\alpha$-subunit of CR3, the ability of CD18-specific mAbs to block ROS production by porcine neutrophils was negligible ( $\beta$-subunit of CR3). Interestingly, blocking dectin-1 by laminarin decreased ROS production as well, albeit not as much as CD11R3-specific mAbs. Although incorporation of antigens inside the particles seems to influence the recognition of GPs by dectin-1, CD11R3 is still the most important receptor for the GP-induced ROS production in porcine neutrophils.

\section{T-cell proliferation is significantly increased when FedF is incorporated inside GPs}

To assess whether GPs could serve as an immune stimulatory antigen delivery system, we investigated the FedF-specific T-cell proliferation after stimulation of MoDCs with FedF-GPs. As illustrated in Figure 4, FedF-loaded GPs promoted the antigen presentation capacity of MoDCs
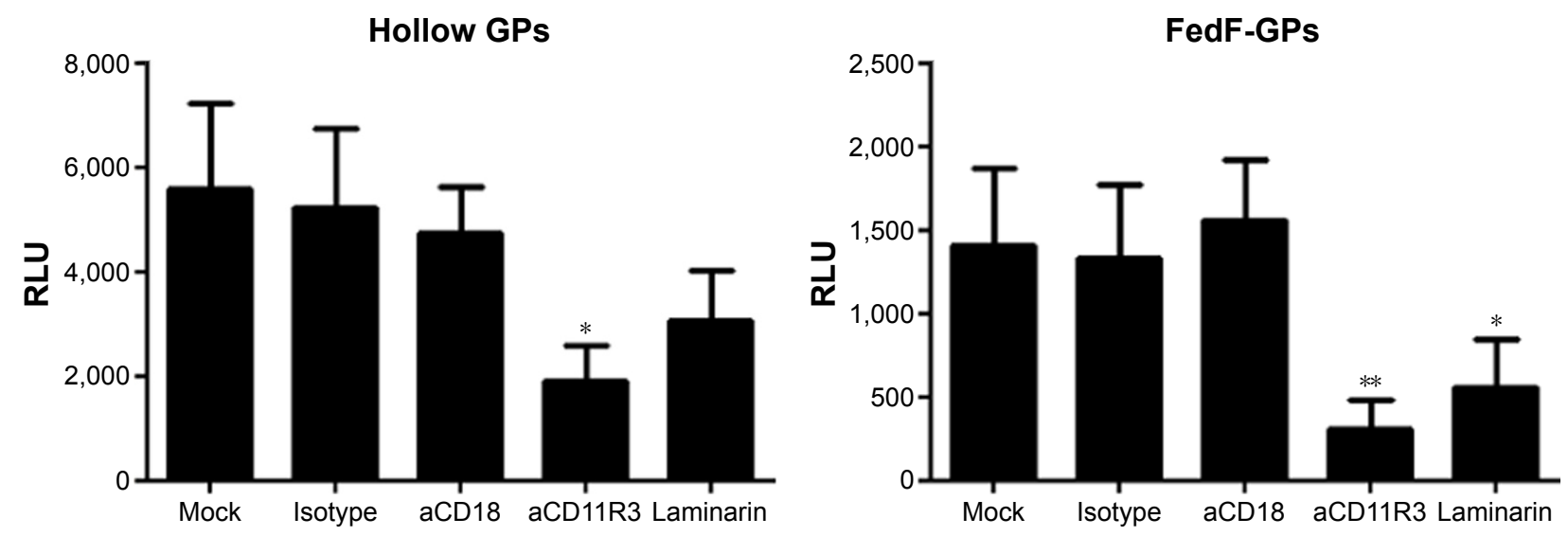

Figure 3 CRI IR3 is involved in the recognition of GPs by neutrophils.

Notes: Neutrophils ( $2 \times 10^{5}$ cells) were incubated with laminarin $(I \mathrm{mg} / \mathrm{mL})$, aCDI $8(5 \mu \mathrm{g} / \mathrm{mL})$, aCDI IR3 (I5 $\left.\mu \mathrm{g} / \mathrm{mL}\right)$, or isotype control (IgG ; I5 $\left.\mu \mathrm{g} / \mathrm{mL}\right)$. Subsequently, the cells were stimulated with $200 \mu \mathrm{g} / \mathrm{mL}$ of the indicated GPs. ROS production was determined via chemiluminescence. Values shown are mean RLU \pm SEM of four pigs. Values of the negative control have been subtracted from the values represented on the graph. $* P<0.05 ; * * P<0.01$.

Abbreviations: IgG, immunoglobulin G; GP, $\beta$-glucan microparticle; RLU, relative light units; ROS, reactive oxygen species; SEM, standard error of the mean. 


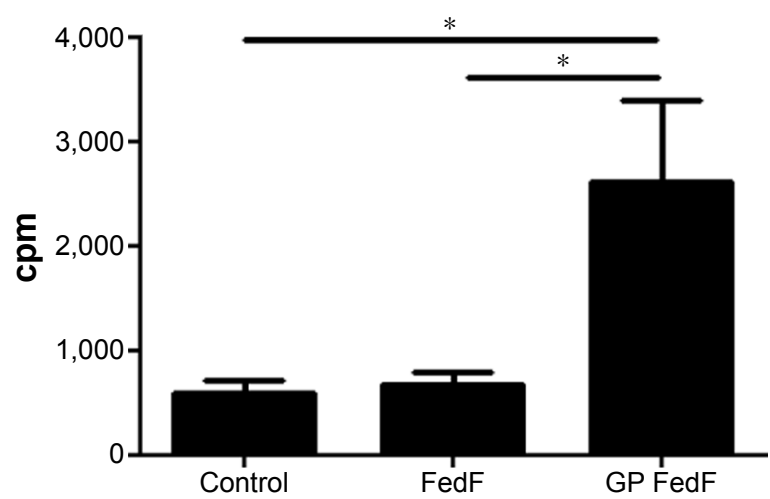

Figure 4 FedF-specific T-cell proliferation is significantly increased when FedF is incorporated inside GPs.

Notes: Encapsulation of FedF in GPs promotes antigen presentation to T-cells by MoDCs. Autologous $\mathrm{CD6}^{+} \mathrm{T}$-cells were cocultured for 5 days with immature, FedF $(8 \mu \mathrm{g})$ or FedF-loaded GPs ( $8 \mu \mathrm{g}$ FedF encapsulated)-stimulated MoDCs. The data represent the mean $\mathrm{cpm} \pm \mathrm{SEM}(\mathrm{n}=4)$. The spontaneous proliferation of the $\mathrm{CD6}^{+}$ responder cells equaled $78 \pm 14 \mathrm{cpm}$, while for ConA-stimulated cells, the proliferation amounted to $15,203 \pm 5,623 \mathrm{cpm}$. Control: immature MoDCs. $* P<0.05$.

Abbreviations: GPs, $\beta$-glucan microparticles; MoDCs, monocyte-derived dendritic cells; cpm, counts per minute; SEM, standard error of the mean.

to porcine $\mathrm{CD}^{+} \mathrm{T}$-cells as compared to immature and FedF-stimulated MoDCs. Surprisingly, FedF stimulation of dendritic cells did not elicit T-cell proliferation, suggesting that FedF has an inhibitory effect on MoDCs. Clearly, the encapsulation of FedF inside immunostimulatory particles avoids this inhibitory effect and hence is necessary to induce T-cell proliferation.

\section{Conclusion}

GPs are emerging particles known for their high antigenloading capacity and safety. In this study, we evaluated the incorporation of a clinically relevant infectious disease antigen FedF, the tipadhesin of F18 fimbriae, inside these particles. The results clearly demonstrate that FedF is incorporated intact inside the particles with a high loading efficiency $(84.5 \%)$. Besides antigen carrier activity, these particles are able to stimulate the innate immune system by binding to the $\alpha$-subunit of CR3. To confirm the duality of these particles, we demonstrated in a $\mathrm{T}$-cell proliferation assay that FedF inside the particles is processed by MoDCs and subsequently presented to T-cells, resulting in their activation and proliferation. Taken together, FedF-loaded GPs are promising vaccine candidates in the protection of pigs against F18 ${ }^{+}$ETEC and STEC infections, and this study motivates exploring this vaccine in vivo.

\section{Acknowledgments}

This research was funded by a $\mathrm{PhD}$ grant of the Agency for Innovation by Science and Technology (IWT) and by Ghent University (Belgium). BD has an FWO postdoctoral grant.

\section{Disclosure}

The authors report no conflicts of interest in this work.

\section{References}

1. Holmgren J, Svennerholm AM. Vaccines against mucosal infections. Curr Opin Immunol. 2012;24(3):343-353.

2. Lycke N. Recent progress in mucosal vaccine development: potential and limitations. Nat Rev Immunol. 2012;12(8):592-605.

3. Malik B, Goyal AK, Mangal S, Zakir F, Vyas SP. Implication of gut immunology in the design of oral vaccines. Curr Mol Med. 2010;10(1): 47-70.

4. Wilkhu J, McNeil SE, Kirby DJ, Perrie Y. Formulation design considerations for oral vaccines. Ther Deliv. 2011;2(9):1141-1164.

5. Bramwell VW, Perrie Y. Particulate delivery systems for vaccines: what can we expect? J Pharm Pharmacol. 2006;58(6):717-728.

6. McNeela EA, Lavelle EC. Recent advances in microparticle and nanoparticle delivery vehicles for mucosal vaccination. Curr Top Microbiol Immunol. 2012;354:75-99.

7. Vyas SP, Gupta PN. Implication of nanoparticles/microparticles in mucosal vaccine delivery. Expert Rev Vaccines. 2007;6(3):401-418.

8. Jiang W, Gupta RK, Deshpande MC, Schwendeman SP. Biodegradable poly(lactic-co-glycolic acid) microparticles for injectable delivery of vaccine antigens. Adv Drug Deliv Rev. 2005;57(3):391-410.

9. Aouadi M, Tesz GJ, Prot M, et al. Glucan particles for selective delivery of siRNA to phagocytic cells in mice. Biochem J. 2011;21(5):A32.

10. De Jesus M, Ostroff GR, Levitz SM, Bartling TR, Mantis NJ. A population of Langerin-positive dendritic cells in murine Peyer's patches involved in sampling beta-glucan microparticles. PLoS One. 2014;9(3): e91002.

11. De Smet R, Verschuere S, Allais L, et al. Spray-dried polyelectrolyte microparticles in oral antigen delivery: stability, biocompatibility, and cellular uptake. Biomacromolecules. 2014;15(6):2301-2309.

12. Huang H, Ostroff GR, Lee CK, et al. Relative contributions of dectin-1 and complement to immune responses to particulate $\beta$-glucans. J Immunol. 2012;189(1):312-317.

13. Huang H, Ostroff GR, Lee CK, Specht CA, Levitz SM. Characterization and optimization of the glucan particle-based vaccine platform. Clin Vaccine Immunol. 2013;20(10):1585-1591.

14. Huang HB, Ostroff GR, Lee CK, Specht CA, Levitz SM. Robust stimulation of humoral and cellular immune responses following vaccination with antigen-loaded $\beta$-glucan particles. MBio. 2010;1(3):e00164-10.

15. Soto E, Ostroff G. Glucan Particles as an Efficient siRNA Delivery Vehicle. NSTI-Nanotech 2008, Technical Proceedings, 2008, Vol 2: 332-335.

16. Soto ER, Caras AC, Kut LC, Castle MK, Ostroff GR. Glucan particles for macrophage targeted delivery of nanoparticles. J Drug Deliv. 2012; 2012:143524.

17. Berner VK, Sura ME, Hunter KW Jr. Conjugation of protein antigen to microparticulate $\beta$-glucan from Saccharomyces cerevisiae: a new adjuvant for intradermal and oral immunizations. Appl Microbiol Biotechnol. 2008;80(6):1053-1061.

18. Hurtgen BJ, Hung CY, Ostroff GR, Levitz SM, Cole GT. Construction and evaluation of a novel recombinant $\mathrm{T}$ cell epitope-based vaccine against coccidioidomycosis. Infect Immun. 2012;80(11):3960-3974.

19. Adachi Y, Okazaki M, Ohno N, Yadomae T. Enhancement of cytokine production by macrophages stimulated with $(1 \rightarrow 3)-\beta$-D-glucan, grifolan (GRN), isolated from Grifola frondosa. Biol Pharm Bull. 1994; 17(12):1554-1560.

20. Williams DL. Overview of $(1 \rightarrow 3)-\beta$-D-glucan immunobiology. Mediators Inflamm. 1997;6(4):247-250.

21. Baert K, Sonck E, Goddeeris BM, Devriendt B, Cox E. Cell type-specific differences in beta-glucan recognition and signalling in porcine innate immune cells. Dev Comp Immunol. 2015;48(1):192-203.

22. De Smet R, Demoor T, Verschuere $S$, et al. $\beta$-Glucan microparticles are good candidates for mucosal antigen delivery in oral vaccination. J Control Release. 2013;172(3):671-678. 
23. Huang HB, Ostroff GR, Lee CK, et al. Relative contributions of dectin- 1 and complement to immune responses to particulate $\beta$-glucans. J Immunol. 2012;189(1):312-317.

24. DebRoy C, Roberts E, Scheuchenzuber W, Kariyawasam S, Jayarao BM. Comparison of genotypes of Escherichia coli strains carrying F18ab and F18ac fimbriae from pigs. J Vet Diagn Invest. 2009; 21(3):359-364.

25. Melkebeek V, Goddeeris BM, Cox E. ETEC vaccination in pigs. Vet Immunol Immunopathol. 2013;152(1-2):37-42.

26. Moonens K, Bouckaert J, Coddens A, et al. Structural insight in histoblood group binding by the F18 fimbrial adhesin FedF. Mol Microbiol. 2012;86(1):82-95.

27. De Kerpel M, Van Molle I, Brys L, Wyns L, De Greve H, Bouckaert J. $\mathrm{N}$-terminal truncation enables crystallization of the receptor-binding domain of the FedF bacterial adhesin. Acta Crystallogr Sect F Struct Biol Cryst Commun. 2006;62:1278-1282.

28. Verdonck F, Tiels P, van Gog K, et al. Mucosal immunization of piglets with purified F18 fimbriae does not protect against F18+ Escherichia coli infection. Vet Immunol Immunopathol. 2007;120(3-4):69-79.

29. Dawson HD, Loveland JE, Pascal G, et al. Structural and functional annotation of the porcine immunome. BMC Genomics. 2013;14:332.

30. Mair KH, Sedlak C, Kaser T, et al. The porcine innate immune system: an update. Dev Comp Immunol. 2014;45(2):321-343.

31. Sonck E, Stuyven E, Goddeeris B, Cox E. The effect of $\beta$-glucans on porcine leukocytes. Vet Immunol Immunopathol. 2010;135(3-4): 199-207.
32. Donne E, Pasmans F, Boyen F, et al. Survival of Salmonella serovar Typhimurium inside porcine monocytes is associated with complement binding and suppression of the production of reactive oxygen species. Vet Microbiol. 2005;107(3-4):205-214.

33. Pescovitz MD, Lunney JK, Sachs DH. Preparation and characterization of monoclonal antibodies reactive with porcine PBL. J Immunol. 1984;133(1):368-375.

34. Inumaru S, Kokuho T, Denham S, et al. Expression of biologically active recombinant porcine GM-CSF by baculovirus gene expression system. Immunol Cell Biol. 1998;76(3):195-201.

35. Carrasco CP, Rigden RC, Schaffner R, et al. Porcine dendritic cells generated in vitro: morphological, phenotypic and functional properties. Immunology. 2001;104(2):175-184.

36. Van der Stede Y, Cox E, Verdonck F, Vancaeneghem S, Goddeeris BM. Reduced faecal excretion of $\mathrm{F}^{+}-E$. coli by the intramuscular immunisation of suckling piglets by the addition of $1 \alpha, 25$-dihydroxyvitamin D or CpG-oligodeoxynucleotides. Vaccine. 2003;21(9-10):1023-1032.

37. Saalmuller A, Aasted B, Canals A, et al. Analyses of monoclonal antibodies reactive with porcine CD6. Vet Immunol Immunopathol. 1994; 43(1-3):243-247.

38. Tiels P, Verdonck F, Coddens A, Ameloot P, Goddeeris B, Cox E. Monoclonal antibodies reveal a weak interaction between the F18 fimbrial adhesin FedF and the major subunit FedA. Vet Microbiol. 2007; 119(2-4):115-120.
International Journal of Nanomedicine

\section{Publish your work in this journal}

The International Journal of Nanomedicine is an international, peerreviewed journal focusing on the application of nanotechnology in diagnostics, therapeutics, and drug delivery systems throughout the biomedical field. This journal is indexed on PubMed Central, MedLine, CAS, SciSearch $®$, Current Contents $\AA /$ Clinical Medicine,

\section{Dovepress}

Journal Citation Reports/Science Edition, EMBase, Scopus and the Elsevier Bibliographic databases. The manuscript management system is completely online and includes a very quick and fair peer-review system, which is all easy to use. Visit http://www.dovepress.com/ testimonials.php to read real quotes from published authors. 